\title{
Plants Secrete Substances That Mimic Bacterial N-Acyl Homoserine Lactone Signal Activities and Affect Population Density-Dependent Behaviors in Associated Bacteria
}

\author{
Max Teplitski, ${ }^{1}$ Jayne B. Robinson, ${ }^{2}$ and Wolfgang D. Bauer ${ }^{1}$ \\ ${ }^{1}$ Horticulture and Crop Science Department, Ohio State University, Columbus 43210, U.S.A.; \\ ${ }^{2}$ Biology Department, University of Dayton, Dayton, OH 45469, U.S.A. \\ Accepted 4 March 2000.
}

\begin{abstract}
In gram-negative bacteria, many important changes in gene expression and behavior are regulated in a population density-dependent fashion by $N$-acyl homoserine lactone (AHL) signal molecules. Exudates from pea (Pisum sativum) seedlings were found to contain several separable activities that mimicked AHL signals in well-characterized bacterial reporter strains, stimulating AHL-regulated behaviors in some strains while inhibiting such behaviors in others. The chemical nature of the active mimic compounds is currently unknown, but all extracted differently into organic solvents than common bacterial AHLs. Various species of higher plants in addition to pea were found to secrete AHL mimic activities. The AHL signal-mimic compounds could prove to be important in determining the outcome of interactions between higher plants and a diversity of pathogenic, symbiotic, and saprophytic bacteria.
\end{abstract}

Additional keywords: chitinase, quorum sensing, swarming, violacein.

In recent years, it has become clear that many important behaviors in bacteria are regulated in a population densitydependent manner, including behaviors such as motility and the synthesis of exoenzymes, exopolysaccharides, surfactants and antibiotics that are crucial to attacking or colonizing plant, animal, or microbial hosts (Eberl et al. 1996; Glessner et al. 1999; for reviews see Fuqua et al. 1996; Pierson et al. 1999; Swift et al. 1999). A recent study has revealed that transcription of over 250 genes is affected by the $N$-acyl homoserine lactone (AHL) signaling system in Pseudomonas aeruginosa (Whiteley et al. 1999). The synthesis of AHL signals is common among plant-associated bacteria (Cha et al. 1998) and AHL signaling has been well studied in several of these bacteria (for review see Pierson et al. 1999).

Bacterial cell-cell signaling and population densitydependent regulation of behavior ("quorum sensing") involves the synthesis and perception of small, diffusible signal molecules that move in and out through the cell membrane and

Corresponding author: W. D. Bauer, Horticulture and Crop Science Department, 2021 Coffey Rd., Ohio State University, Columbus 43210, U.S.A.; Telephone: 1-614-292-9035; E-mail: bauer.7@osu.edu between cells. In gram-negative bacteria, AHLs are the best studied of the diffusible signal compounds that govern population density-dependent behaviors, but there is recent evidence for other types of intercellular signal compounds, including cyclic dipeptides and quinolones in $P$. aeruginosa (Holden et al. 1999; Pesci et al. 1999), unknown low molecular weight substances in Xanthomonas campestris (Poplawsky et al. 1998), and a volatile fatty acid methyl ester in Ralstonia solanacearum (Flavier et al. 1997). In gram-positive bacteria, many behaviors are also regulated in a population densitydependent manner (cf. reviews by Dunny and Leonard 1997; Horinouchi 1999; Lazazzera et al. 1999). The quorum-sensing signal substances in gram-positive species have been identified as $\gamma$-butyrolactones, structurally quite similar to AHLs, and post-translationally modified peptides.

A given bacterial species will commonly synthesize several different AHL signals that differ from one another in the length of the $N$-acyl side chain (four to 14 carbons), the presence or absence of double bonds, or side chain substituents (keto, hydroxyl) (Swift et al. 1999). AHLs usually have their effects by binding semi-specifically to receptor proteins homologous to LuxR, the prototypical AHL receptor from Vibrio fischeri (Choi and Greenberg 1992; Fuqua et al. 1996; McClean et al. 1997). At sufficiently high population densities, the AHLs reach a "threshold" concentration so that AHL binding to the cognate LuxR-like receptor activates the transcription of specific genes or sets of genes (Stevens and Greenberg 1999). A given bacterial species may have several different LuxR-like receptors for AHLs, each controlling different behaviors. In some cases, AHL binding to a receptor induces increased synthesis of the AHL, leading to rapidly self-amplifying behavioral changes in a set of cells (Fuqua et al. 1996). In other cases, the binding of one AHL controls the synthesis of one or more other AHLs, leading to complex regulatory hierarchies (Pesci and Iglewski 1999; Rodelas et al. 1999). There is evidence that AHLs secreted by cells of one species can induce population density-dependent responses in cells of other bacterial species in natural rhizosphere environments (Pierson et al. 1998). Such interpopulation AHL signaling may be significant to bacterial communities.

An important recent study has demonstrated that halogenated furanones produced by the marine red algae Delisea pul- 
chra are able to disrupt AHL-regulated behaviors in Serratia liquefaciens and other bacterial species (Givskov et al. 1996; Kjelleberg et al. 1997). The furanones are structurally similar to AHLs, and there is biochemical evidence that the furanones inhibit the induction of AHL-stimulated behaviors by binding competitively to the AHL receptor protein (Manefield et al. 1999). Thus, the furanones of D. pulchra are genuine AHL signal-mimic compounds, structurally analogous to AHLs and able to affect AHL-regulated behaviors. There is also evidence that the furanones have significant effects on bacterial colonization of the alga, both in vitro and in natural marine environments (Kjelleberg et al. 1997). The discovery of AHL signal-mimic compounds in an alga raises the possibility that higher plants might also synthesize and secrete compounds that mimic the activity of bacterial AHL signal compounds. The secretion of AHL mimic compounds could have important effects on bacterial colonization and infection of host plants, and might be of considerable medical and agricultural interest.

In attempting to learn whether higher plants secrete substances that mimic AHL signal molecules in regulating population density-dependent behaviors, we have relied on several bacterial reporter strains carefully developed by others to detect exogenous AHLs, specifically the Chromobacterium violaceum strain CV026 (McClean et al. 1997), the S. liquefaciens strains MG44 and PL10 (Givskov et al. 1996, Lindum et al. 1998), Pseudomonas aureofaciens 30-84I (Wood et al. 1997), and plasmid AHL reporters in Escherichia coli (Winson et al. 1998; Swift et al. 1997) carrying a luxCDABE cassette activated by the LuxR receptor of Vibrio fischeri, the AhyR receptor of Aeromonas hydrophila, or the LasR receptor of $P$. aeruginosa. Strains of $P$. aureofaciens, $P$. aeruginosa, $C$. violaceum, and $S$. liquefaciens are often found in association with plants and the latter three species have also been recognized as opportunistic pathogens of humans (e.g., Gupta et al. 1999; Hussain and Vancura 1970; Grimont and Grimont 1978; Miller et al. 1988). The S. liquefaciens wild-type strain, MG1, was isolated from diseased cucumber (Givskov et al. 1997) and wild-type $P$. aureofaciens $30-84$ is an effective biocontrol strain in the wheat rhizosphere (Pierson and Thomashow 1992). Our results indicate that the secretion of AHL signalmimic compounds capable of affecting AHL-regulated behaviors in associated bacteria is common among higher plants.

\section{RESULTS}

\section{C. violaceum wild type and CV026 reporter.}

The CV026 reporter strain is a mutant of wild-type $C$. violaceum ATCC 31532, which cannot synthesize $\mathrm{N}$ hexanoyl-L-homoserine lactone $\left(=\mathrm{C}_{6}\right.$-HSL). It is thus reliant on exogenously added AHLs for activation of its AHL receptor, CviR, to induce synthesis of the purple antibiotic violacein and a number of exoenzymes (McClean et al. 1997; Chernin et al. 1998; Swift et al. 1999). Violacein production in CV026 is induced by AHLs with a short $\left(\mathrm{C}_{4}-\mathrm{C}_{8}\right)$ alkanoyl or 3-oxo-alkanoyl side chain or by a number of their chemical analogs (McClean et al. 1997; Cha et al. 1998). Addition of an AHL with a long alkanoyl or 3-oxo-alkanoyl side chain (e.g., 3-oxo- $\mathrm{C}_{12}$-HSL) competitively inhibits violacein synthesis induced by short side chain AHLs such as $\mathrm{N}$-butanoyl-Lhomoserine lactone $\left(=\mathrm{C}_{4}\right.$-HSL). Thus, CV026 is an excellent reporter for a wide range of bacterial AHLs (or AHL signalmimic compounds from plants).

AHL-regulated behaviors in $C$. violaceum CV026 were strongly inhibited by substances secreted by pea seedlings. When 5-day-old, aseptically grown pea seedlings were placed on the surface of nutrient agar colonized by a lawn of the CV026 reporter strain, the seedlings induced no detectable violacein synthesis (Fig. 1A), in contrast to the positive $\mathrm{C}_{4}$-HSL control (Fig. 1C). However, when placed on agar containing $4 \mu \mathrm{M} \mathrm{C}_{4}$-HSL, the pea seedlings visibly inhibited $\mathrm{C}_{4}$-HSL-induced violacein synthesis in the lawn of CV026, leaving colorless areas around the seedlings (Fig. 1B). No inhibition of bacterial growth around the seedlings was observed, and none was detected in subsequent assays of CV026 growth in shake cultures containing pea exudates. The inhibition of violacein synthesis in areas adjacent to the seedlings was similar to that caused by the addition of a long chain AHL to a lawn of $\mathrm{C}_{4}$-HSL-induced CV026 (see Figure 1D, and McClean et al. 1997).

Substances that inhibited AHL-induced violacein synthesis in $C$. violaceum $\mathrm{CV} 026$ were present in crude exudates collected by gentle rinsing of aseptically grown pea seedlings and in methanol extracts of lyophilized exudate. As shown in Figure $2 \mathrm{~A}, \mathrm{C}_{4}$-HSL-inducible violacein synthesis was inhibited by a methanol extract of pea exudate in rough proportion to the amount of extract added. Inhibition of violacein synthesis by the extract could be partially prevented or reversed by an

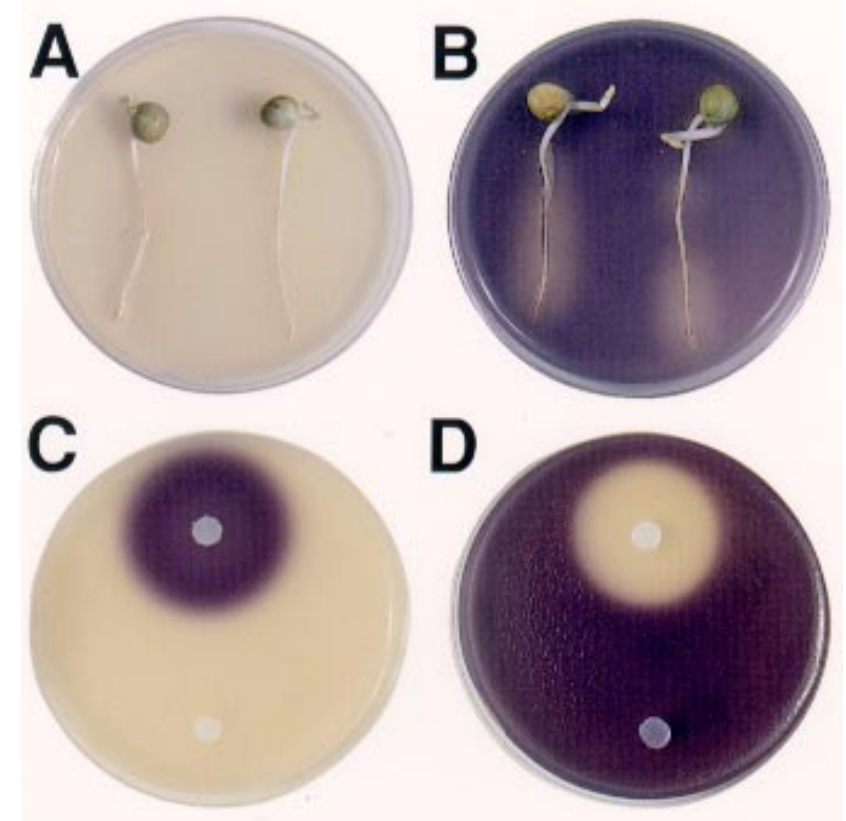

Fig. 1. Induction and inhibition of violacein synthesis in Chromobacterium violaceum $\mathrm{CV} 026$ by $\mathrm{N}$-acyl homoserine lactones (AHLs) and pea seedlings. Direct assays: A, Aseptically grown 7-day-old pea seedlings $18 \mathrm{~h}$ after contact with a lawn of CV026 in a layer of Luria-Bertani (LB) soft agar on a base of LB agar; C, Filter disks containing either $3.5 \mu \mathrm{g}$ of $\mathrm{C}_{4}$-HSL (top) or no AHL (bottom) after $18 \mathrm{~h}$ of incubation on a lawn of CV026 in a layer of LB soft agar on a base of LB agar. Indirect assays: B, Pea seedlings $18 \mathrm{~h}$ after contact with a lawn of CV026 in a 5-ml layer of LB soft agar containing $3 \mu \mathrm{M} \mathrm{C}_{4}-\mathrm{HSL}$ on a base of $15 \mathrm{ml}$ of LB agar; D, Filter disks containing either $3 \mu \mathrm{g}$ of 3-oxo- $\mathrm{C}_{12}$-HSL (top) or no AHL (bottom) after $18 \mathrm{~h}$ of incubation on a lawn of CV026 in a 5-ml layer of LB soft agar containing $3 \mu \mathrm{M} \mathrm{C}_{4}-\mathrm{HSL}$ on a base of $15 \mathrm{ml}$ of LB agar. 
initial addition of twice as much $\mathrm{C}_{4}$-HSL to the assay wells (Fig. 2B) or to the area adjacent to live seedlings (not shown). Little restoration of violacein synthesis was seen if additional $\mathrm{C}_{4}$-HSL was added after $4 \mathrm{~h}$ or later. We have observed that CV026 cells remain responsive to $\mathrm{C}_{4}$-HSL induction of violacein synthesis for a limited time while they are actively growing (data not shown), perhaps accounting for the failure of delayed additions of $\mathrm{C}_{4}$-HSL to more fully restore exudateinhibited violacein synthesis. The progressively greater inhibition of AHL-induced violacein synthesis by greater amounts of pea exudate and the partial reversal of such inhibition by additional $\mathrm{C}_{4}$-HSL both suggest, but do not prove, that pea seedlings secrete one or more substances capable of specifically interfering with the perception of $\mathrm{C}_{4}$-HSL by CV026.

To more rigorously test the possible disruption of AHL signaling in $C$. violaceum by substances in pea exudates, we examined the effects of methanol extract preparations on extracellular protease and chitinase activities, both of which are also regulated by the same receptor for AHL signals as violacein synthesis in C. violaceum (Chernin et al. 1998; Swift et al.
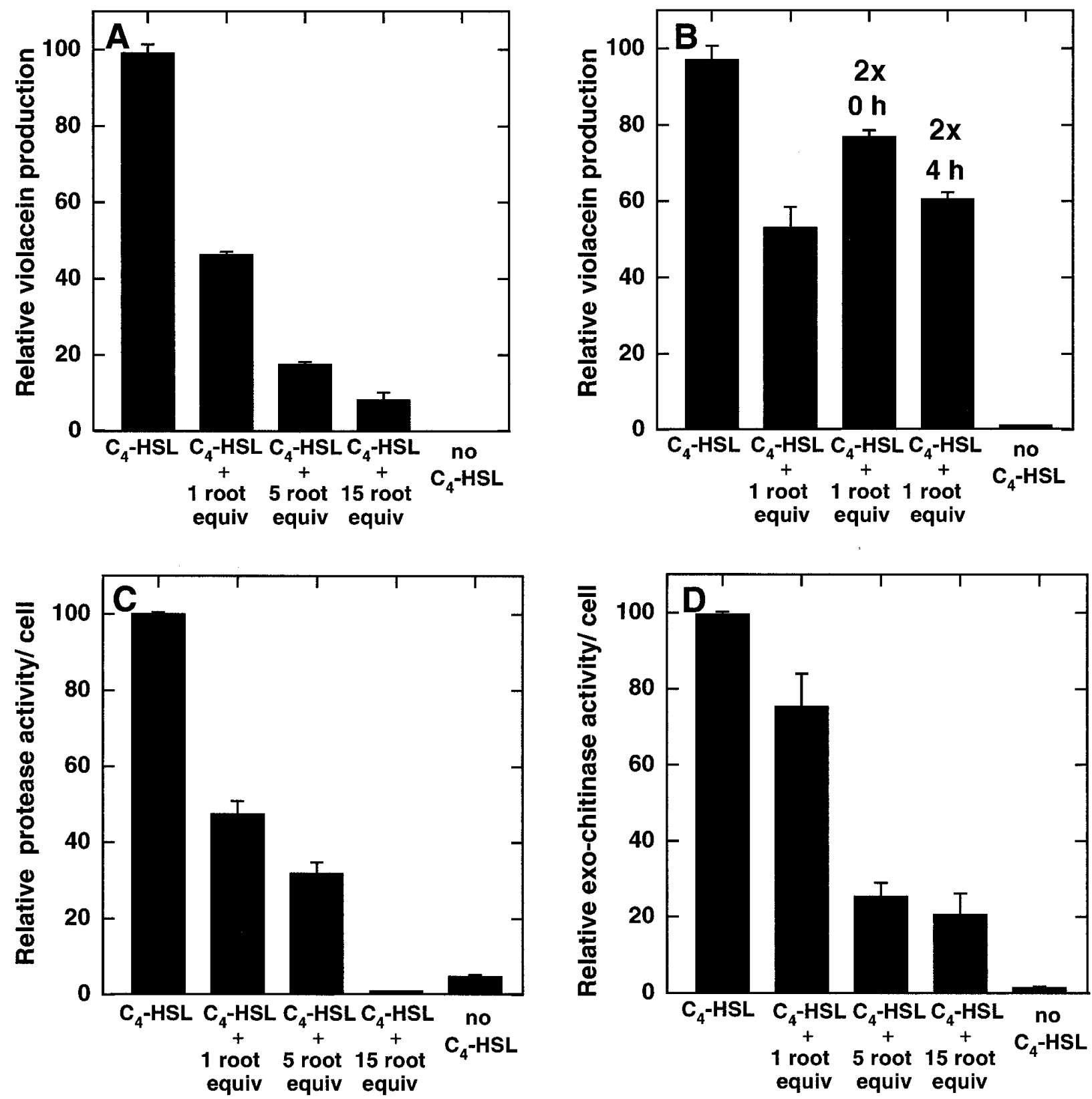

Fig. 2. Effects of pea seedling exudates on violacein synthesis and exoenzyme activities in the CV026 reporter strain. A, Violacein production induced by $0.5 \mu \mathrm{g}(3 \mu \mathrm{M})$ of $\mathrm{C}_{4}$-HSL per ml in the presence or absence of pea exudate was assayed colorimetrically after $20 \mathrm{~h}$ of incubation. B, An additional 0.5 $\mu \mathrm{g}$ of $\mathrm{C}_{4}$-HSL per $\mathrm{ml}$ was added either 0 or $4 \mathrm{~h}$ after suspension of CV026 cells in fresh medium, with or without one seedling equivalent of the pea exudate extract, and violacein production assayed colorimetrically after $20 \mathrm{~h}$. C, Extracellular protease activity induced after $20 \mathrm{~h} \mathrm{by} 0.5 \mu \mathrm{g}$ of $\mathrm{C}_{4}$-HSL per $\mathrm{ml}$ in the presence or absence of pea exudate. D, Exochitinase (p-nitrophenyl- $\beta$-D- $N$-acetylglucosaminidase) activity induced after $20 \mathrm{~h} \mathrm{by} 0.5 \mu \mathrm{g}$ of $\mathrm{C}_{4}{ }^{-}$ HSL per $\mathrm{ml}$ in the presence or absence of pea exudate. All assays were performed in duplicate in repeated experiments as described in Materials and Methods. 
1999). As shown in Figure $2 \mathrm{C}$ and $\mathrm{D}$, the addition of seedling exudate extract substantially inhibited both $\mathrm{C}_{4}$-HSL-inducible protease and $\mathrm{N}$-acetylglucosaminidase (exochitinase) activities in CV026. When assayed on colloidal chitin plates as described by Chernin et al. (1998), pea seedling exudates also substantially inhibited AHL-dependent endochitinase activity (data not shown). Growth of CV026 was not appreciably altered by pea exudates in these experiments, as determined by plate counts and absorbance measurements (data not shown). In other control experiments, CV026 cultures were first incubated with $\mathrm{C}_{4}$-HSL to induce extracellular protease and $\mathrm{N}$-acetylglucosaminidase, then mixed with methanol-extracted substances from pea exudate and immediately assayed. Addition of the pea exudate extract after induction by $\mathrm{C}_{4}$-HSL had no effect on these activities, indicating that the extracts did not contain substances that directly inhibited the enzymes. When $\mathrm{C}_{4}$-HSL was incubated overnight at room temperature with high-pressure liquid chromatography (HPLC)-purified pea extracts containing the violacein inhibitory activity, it was found that the $\mathrm{C}_{4}-\mathrm{HSL}$ could be fully recovered from the mixture by ethyl acetate extraction (data not shown), suggesting that the active materials in seedling exudates did not degrade or immobilize the exogenously added $\mathrm{C}_{4}$-HSL. Based on these results, it seems unlikely that the coordinate inhibition of AHL-induced violacein, protease, and chitinases by pea exudates seen in Figure 2 is an artifact of some nonspecific interference with growth, violacein biosynthesis, exoenzyme synthesis or activity, or $\mathrm{C}_{4}-\mathrm{HSL}$ availability. Reasonable mechanisms of action to consider include direct interactions of the plant compounds with the receptor, CviR (as expected for a true signal-mimic compound like the D. pulchra furanones) or indirect effects such as reduced bacterial uptake of the exogenously added $\mathrm{C}_{4}$-HSL.

As shown in Figure 3, AHL-regulated extracellular protease activity was inhibited by pea exudate extracts to about the

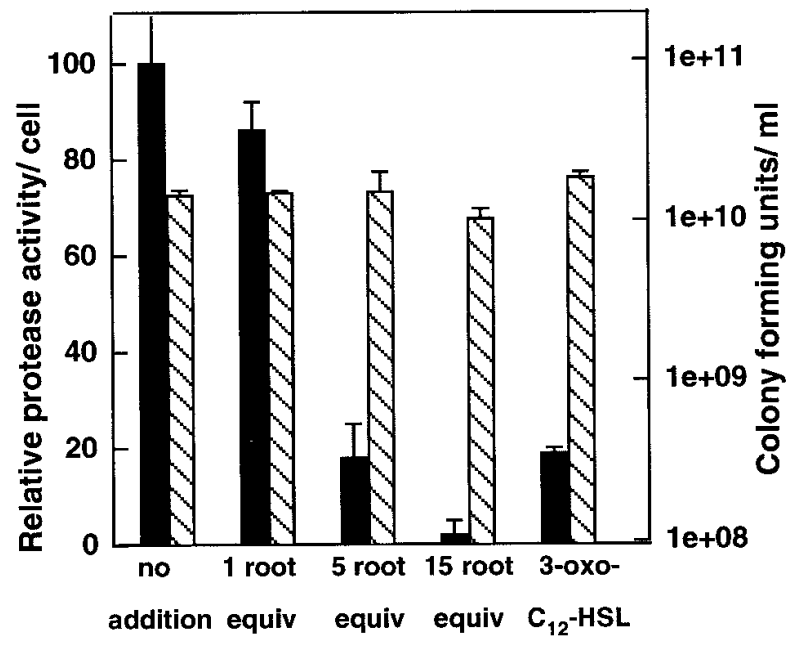

Fig. 3. Effects of pea seedling exudate on growth and $\mathrm{N}$-acyl homoserine lactone (AHL)-regulated extracellular protease activity in wild-type Chromobacterium violaceum. Solid bars show average extracellular protease activity $( \pm \mathrm{SE})$ in the supernatant of wild-type $C$. violaceum cells after $20 \mathrm{~h}$ in the presence or absence of pea exudate extract or $4 \mu \mathrm{M}$ 3 -oxo- $\mathrm{C}_{12}$-HSL. Hatched bars show growth of wild-type $C$. violaceum $( \pm \mathrm{SE})$ after $20 \mathrm{~h}$ in the presence or absence of pea exudate extract or 4 $\mu \mathrm{M}$ 3-oxo- $\mathrm{C}_{12}$-HSL. Growth and protease activity on azocasein were assayed in duplicate in repeated experiments as described in Materials and Methods. same extent in wild-type $C$. violaceum as in the CV026 reporter strain supplied with exogenous $\mathrm{C}_{4}$-HSL. Pea exudate from five seedlings was about as effective as $4 \mu \mathrm{M}$ exogenous 3-oxo- $\mathrm{C}_{12}$-HSL, a known competitive inhibitor of violacein synthesis (McClean et al. 1997). The addition of pea exudate extract or 3-oxo- $\mathrm{C}_{12}$-HSL had no appreciable effect on growth of the bacteria (Fig. 3). These results are important because they suggest that the normal synthesis of cognate AHLs $\left(\mathrm{C}_{6^{-}}\right.$ HSL in this case) by wild-type bacteria may not be able to mask or overwhelm the effects of secreted plant signal-mimic compounds in natural encounters. Further studies are clearly needed to explore the question of just how effectively the plant compounds can compete with endogenously synthesized AHLs to affect behavior in wild-type bacteria.

\section{S. liquefaciens reporters.}

In wild-type $S$. liquefaciens MG1, the initiation of swarming requires surface-stimulated induction of the $f l h D C$ operon, leading to formation of hyperflagellated cells (Givskov et al. 1997). Surface swarming also depends on $\mathrm{C}_{4^{-}}$and/or $\mathrm{C}_{6}$-HSLinduced synthesis of serrawettin, a lipopeptide surfactant (Eberl et al. 1999). The S. liquefaciens strain MG44 is a swrI::Tn5 mutant of MG1 that cannot synthesize its own $\mathrm{C}_{4}$-HSL and $\mathrm{C}_{6}$-HSL and therefore requires exogenous AHLs for induction of serrawettin synthesis and swarming motility (Lindum et al. 1998). Kjelleberg et al. (1997) used MG44 as a reporter to show that the halogenated furanones of $D$. pulchra inhibited AHL-induced surface swarming and other AHL-regulated behaviors in S. liquefaciens (as well as violacein synthesis in $C$. violaceum). They subsequently showed that serrawettin synthesis required expression of the $s w r A$ gene and isolated PL10, an swrA::Tn5luxAB mutant derivative of MG44. Thus, PL10 serves as a specific transcriptional bioluminescence reporter for the presence of exogenous AHLs capable of binding to the AHL receptor (SwrR) that activates the swrA gene and serrawettin synthesis (Lindum et al. 1998).

As shown in Figure 4, S. liquefaciens swarming was strongly affected by substances secreted by pea seedlings. The reporter strain MG44, unable to make its own AHLs, grew rapidly on the agar surface, but did not swarm (Fig. 4A). When aseptically grown pea seedlings were inoculated with MG44, placed on nutrient agar, and incubated overnight, the seedlings induced the bacteria to swarm outward over the agar surface (Fig. 4B). As controls, toothpicks were inoculated with MG44 in the same manner. The inoculated toothpicks developed dense bacterial growth along their length, but did not induce surface swarming (Fig. 4C) unless previously dipped in a solution of $\mathrm{C}_{4}$-HSL (Fig. 4D). A methanol extract of pea seedling exudate, equivalent to the amount secreted by one 7-day-old pea seedling, strongly stimulated swarming of MG44 when present on a filter disk with the bacteria (Fig. 4E).

The $S$. liquefaciens strain PL10 was used to test whether the plant-induced swarming of MG44 (Fig. 4B and E) was caused by secretion of a surfactant by the seedlings. Since PL10 is defective in both AHL and serrawettin synthesis, it does not swarm even in the presence of exogenous AHLs. However, PL10 can be stimulated to swarm by exogenous serrawettin or other surfactants (Lindum et al. 1998). PL10 thus provides a direct bioassay for exogenous surfactants. As shown in Figure 4F, pea seedlings did not induce surface swarming of PL10, 
indicating that pea does not secrete a surfactant capable of stimulating swarming.

While pea seedlings and methanol extracts of seedling exudate had no effect on swarming of PL10, they did stimulate AHL-dependent luminescence in this reporter, as described below.

\section{Other AHL reporters.}

Another set of AHL reporters was recently developed for sensitive, quantitative, real-time detection of exogenous AHLs (Swift et al. 1997; Winson et al. 1998). These AHL reporters normally function as multicopy plasmids in E. coli (a species that does not synthesize AHLs). The plasmids carry a gene for an AHL receptor protein (the LuxR receptor from $V$. fisheri, AhyR from A. hydrophila, or LasR from $P$. aeruginosa). Upon addition of an appropriate AHL, the receptor is activated so that it binds to its cognate luxI promoter and initiates transcription of a luxCDABE cassette, generating luminescence that is proportional to the concentration of added AHL (Winson et al. 1998). These three reporters differ in their sensitivity to a series of alkanoyl and 3-oxo-alkanoyl homoserine lactones (Winson et al. 1998). For example, the LuxRI' reporter (pSB401) responds strongly to nanomolar concentrations of 3-oxo- $\mathrm{C}_{6}$-HSL and to micromolar concentrations of $\mathrm{C}_{6}$-HSL and 3-oxo- $\mathrm{C}_{12}$-HSL, whereas the LasRI' reporter (pSB1075) responds strongly to nanomolar concentrations of 3-oxo- $\mathrm{C}_{12}$-HSL and $\mathrm{C}_{12}$-HSL (Winson et al. 1998). The AhyRI' reporter (pSB536) responds most strongly to $\mathrm{C}_{4}$-HSL, its cognate AHL signal (Swift et al. 1997). Thus, collectively, these three reporters can detect a fairly broad diversity of AHLs (or AHL signal-mimic compounds).

Figure 5 shows the luminescence of these three E. coli plasmid reporters and that of S. liquefaciens PL10 after inoculation onto live, 4-day-old pea seedlings. The digital images of the seedlings were overlaid with false color luminescence images taken with a very sensitive Hamamatsu charged couple device (CCD) camera 8 to $9 \mathrm{~h}$ after inoculation. The luminescence induced in the reporter strains by the pea seedlings was generally two- to 20 -fold above levels of the noAHL controls. The pea seedlings induced luminescence in each reporter that was an appreciable fraction (10 to 75\%) of the maximal levels obtainable with high concentrations of an appropriate AHL. This suggests that the concentration of putative AHL mimic compounds at the plant surface may be high enough to affect AHL-regulated gene expression in wildtype bacteria in natural encounters.

Plant-to-plant variation in luminescence was most frequently within about twofold for each of the reporters. The intensity of luminescence was normally greatest on the lower $2 / 3$ of the pea root for each of the four AHL luminescence reporters. Luminescence was usually low on the upper portion of the root, the epicotyl, and the cotyledons. It will be of inter-
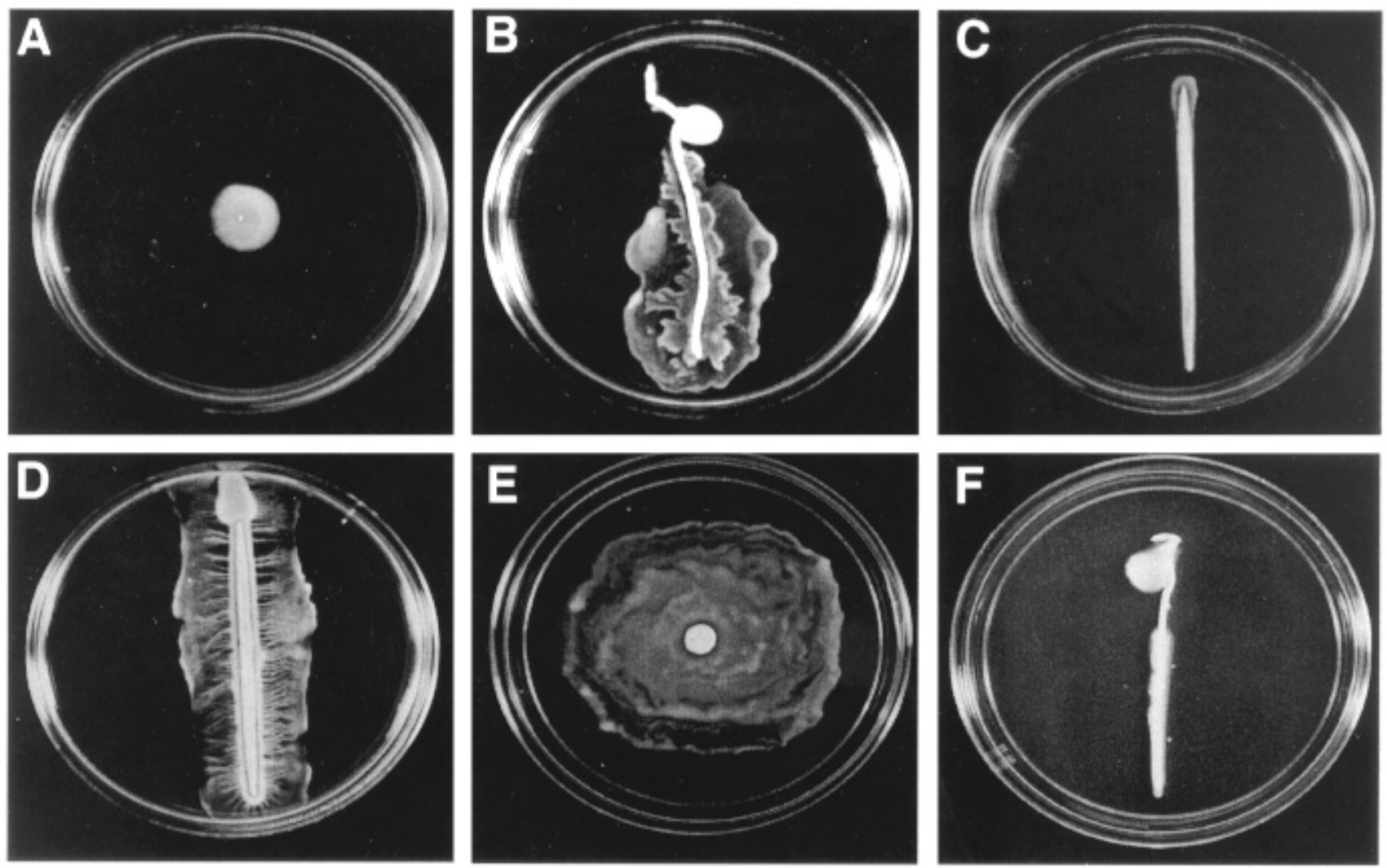

Fig. 4. Effects of pea seedlings and seedling exudates on $N$-acyl homoserine lactone (AHL)-dependent swarming of the Serratia liquefaciens MG44 reporter strain. Aseptically grown pea seedlings and toothpick controls were inoculated with a suspension of S. liquefaciens MG44 cultured as described in Materials and Methods. Inoculated seedlings or toothpicks were then placed on AB glucose-Casamino Acid agar and incubated for 18 to $20 \mathrm{~h}$. A, Filter disk inoculated with MG44. B, Pea seedling inoculated with MG44. C, Sterile toothpick inoculated with MG44. D, Sterile toothpick dipped in $0.5 \mu \mathrm{g}$ of $\mathrm{C}_{4}$-HSL per ml, then inoculated with MG44. E, Filter disk containing 1 seedling equivalent of an evaporated 50\% methanol-water extract of pea seedling exudate and inoculated with MG44. F, Pea seedling inoculated with PL10. 
est to determine whether this pattern of luminescence reflects differences in the relative amounts of putative AHL mimic compounds secreted by the plant in these different parts of the seedlings or reflects differences in the number or metabolic vigor of associated bacterial reporter cells.

The ability of pea seedlings to stimulate the E. coli plasmid reporters provides prima facie evidence that at least some of the active plant compounds interact directly and specifically with the AHL receptor protein and affect its ability to initiate transcription of the luxCDABE cassette. In the E. coli plasmid reporters, there is essentially nothing else for exogenous substances to interact with to induce luminescence. The seedlinginduced luminescence of PL10 is also consistent with direct interaction of the plant substances with the SwrR receptor, with resultant transcriptional activation of $s w r A:: \operatorname{Tn} 5 \operatorname{lux} A B$. In $S$. liquefaciens, however, there may be other, unknown mechanisms for activation of the swrA gene.

\section{AHL signal-mimic activity in other plant species.}

Aseptically grown, uncontaminated seedlings of several other plant species were assayed for possible secretion of AHL mimic activity with the above reporter strains in the same manner as shown in Figures 1, 4, and 5 for pea. None of the plant species tested were able to stimulate detectable violacein synthesis in $C$. violaceum $\mathrm{CV} 026$ or phenazine synthesis in the P. aureofaciens 30-84I reporter (data not shown). Only pea and crown vetch secreted compounds that inhibited AHL-induced synthesis of violacein in the $C$. violaceum CV026 reporter strain, doing so without any apparent inhibi- tion of growth of the reporter strain (Table 1). Rice, soybean, tomato, crown vetch, and Medicago truncatula all activated AHL-dependent swarming in S. liquefaciens MG44 (data not shown). As indicated in Table 1 , these plant species also stimulated luminescence in S. liquefaciens PL10 and in at least one of the three E. coli plasmid reporters. Neither lettuce nor Arabidopsis thaliana stimulated significant activity in any of the reporter strains under our assay conditions. The results from this small survey suggest that secretion of AHL signalmimic compounds may be widespread among higher plants and at least quantitatively variable among species. This is what one might expect if AHL mimic synthesis by plants were an important and co-evolved mechanism for dealing with associated bacteria.

\section{Initial purification and characterization of the AHL signal-mimic substances.}

The chemical nature of the substances from pea that affected AHL-inducible behaviors in the C. violaceum, S. liquefaciens, and E. coli plasmid reporters is presently unknown. The addition of homoserine at concentrations equivalent to or 10-fold higher than those found in pea root exudates (van Egeraat 1975) had no effect in the S. liquefaciens MG44 swarming assay or $C$. violaceum CV026 violacein assays. When 10-mg samples of lyophilized pea seedling exudate were successively extracted with 20 -ml portions of chloroform, ethyl acetate, $100 \%$ methanol, and 1:1 methanol-water, no activity was detectable in the chloroform or ethyl acetate extracts by either the direct or indirect $C$. violaceum assays or
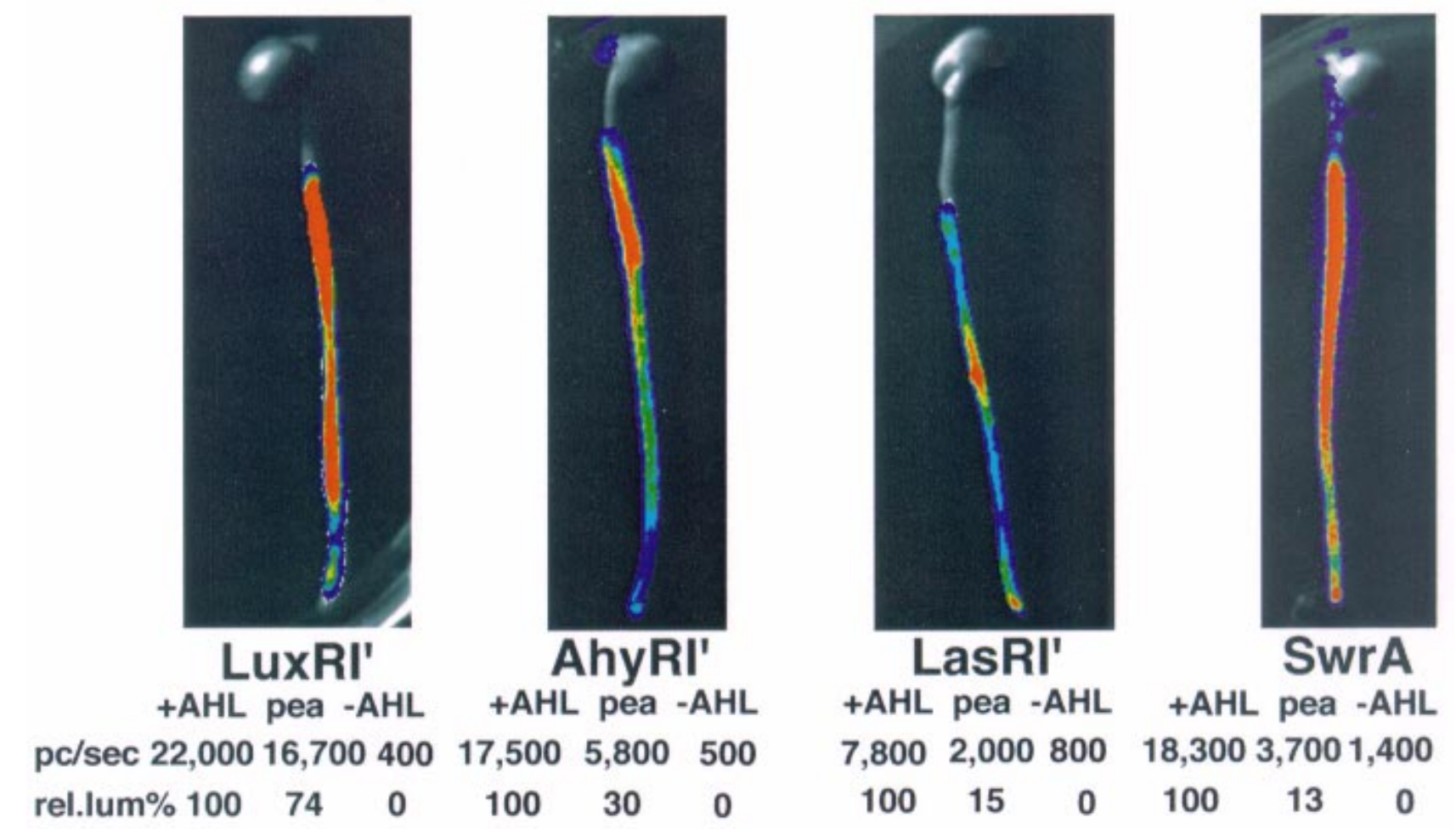

Fig. 5. Pea seedling-induced luminescence of $N$-acyl homoserine lactone (AHL) reporter strains. Luminescence of reporter strains on seedling surfaces was measured and imaged as described in Materials and Methods. Intensity of luminescence is indicated by color (red $>$ yellow $>$ green $>$ blue) and by numbers (photon counts per second). Relative luminescence of reporters on seedlings is also given as a percentage of maximum luminescence inducible by exogenous AHL, normalized to equal numbers of bacteria. Normally, about $1-2 \times 10^{6}$ cells of the Escherichia coli plasmid reporter strains and about $5 \times 10^{7}$ cells of the PL10 reporter were recovered per seedling. Results are representative of several independent experiments. 
by the $S$. liquefaciens swarming or luminescence assays. Chloroform and ethyl acetate can extract the known AHLs made by bacteria, and did extract exogenously added $\mathrm{C}_{4}$-HSL from crude pea exudate preparations (data not shown). Thus,

Table 1. Responses of $N$-acyl homoserine lactone (AHL) reporter strains to substances secreted by seedlings of various plant species

\begin{tabular}{lccccc}
\hline & & \multicolumn{3}{c}{$\begin{array}{c}\text { Relative response of luminescence } \\
\text { reporters (\%) }\end{array}$} \\
\cline { 3 - 7 } Plant & CV026 $^{\mathbf{b}}$ & $\mathbf{P L 1 0}$ & AhyRI' $^{\prime}$ & LasRI' $^{\mathbf{2}}$ & LuxRI' $^{\prime}$ \\
\hline Pea & $* * *$ & 13,35 & 18,30 & 17,25 & 40,74 \\
Crown vetch & $* *$ & 68,100 & 1,2 & 2,4 & 0 \\
Medicago truncatula & 0 & 21 & 15,17 & 15,15 & 1,2 \\
Rice & 0 & 18,27 & 3,4 & 17,37 & 5,6 \\
Lettuce & 0 & 0 & 0 & 0 & 0 \\
Soybean & 0 & 16,21 & 7,42 & 6,53 & 3,9 \\
Tomato & 0 & 23,49 & 2,3 & 3,8 & 0 \\
Arabidopsis thaliana & 0 & 0 & 0 & 0 & 0 \\
\hline
\end{tabular}

a Photon counts per second from two individual 4-day-old seedlings inoculated with a luminescence-based reporter strain were measured with the charged couple device (CCD) camera as described in Materials and Methods. Relative luminescence of each seedling is reported individually, and was calculated by subtracting background luminescence of the no-AHL controls from the luminescence of each seedling and expressing the remainder as a percentage of the luminescence of the + AHL controls, normalized to equal numbers of reporter bacteria. Similar results were obtained in repeated experiments.

${ }^{\mathrm{b}}$ Relative inhibition of AHL-induced violacein synthesis. $* * *=$ very strong; $* *=$ strong it appears that the plant substances with AHL signal activity are chemically different from bacterial AHLs.

Almost all of the activity in crude pea exudate preparations and detectable by the S. liquefaciens swarming and bioluminescence assays was present in $100 \%$ methanol extracts. Microtiter plate dilution endpoint assays could detect about $1 / 4$ of one seedling's activity in the methanol extracts with the PL10 luminescence reporter and X-ray film as described in Materials and Methods (data not shown). Swarm plate assays with MG44 reached a dilution endpoint at extract concentrations roughly fivefold higher than in the luminescence assays, and were considerably more variable. The activity detectable by the $C$. violaceum $\mathrm{CV} 026$ indirect assay was usually present in the $50 \%$ methanol:water extract, although it could be fully, or almost fully, extracted into $100 \%$ methanol if freshly lyophilized material was used. About $1 / 8$ of one seedling's activity could be detected by dilution endpoint assays of violacein production with the CV026 reporter, as described in Materials and Methods (data not shown). Thus, essentially all of the AHL mimic substances secreted by pea and detectable with these reporters are soluble in $100 \%$ methanol. From these semiquantitative estimates of recovered activity, it seems that the mimic substances may be secreted in sufficient quantities to affect AHL-mediated behaviors of bacteria associated with the plant surface in a natural environment. This is consistent with the effects of intact, live seedlings on the behavior of the reporter strains (Figs. 1, 4, and 5).

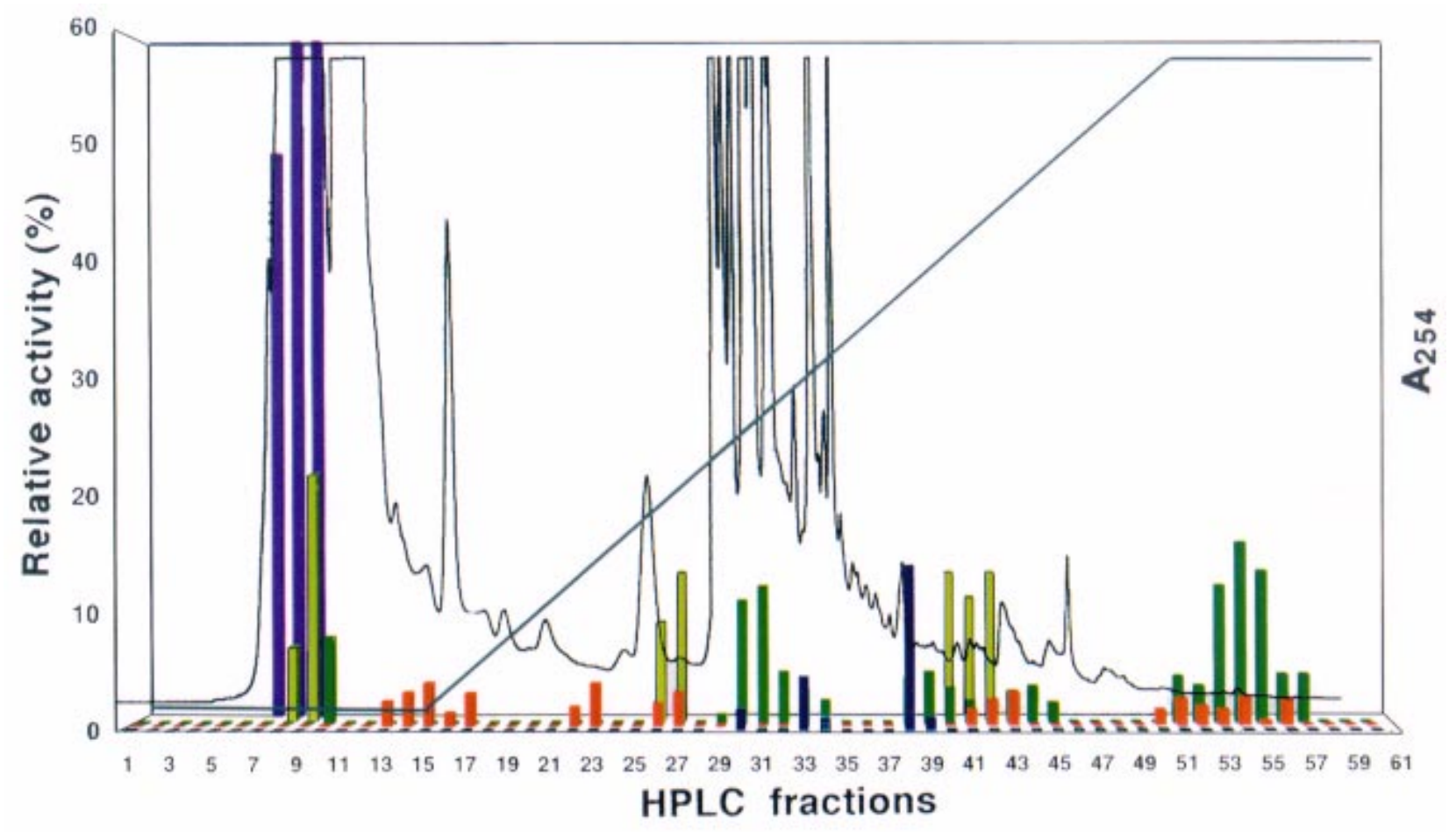

Fig. 6. High-pressure liquid chromatography (HPLC) fractionation of $N$-acyl homoserine lactone (AHL) mimic activities present in methanol extracts of pea seedling exudate. Fractions from a $\mathrm{C}_{18}$ reverse phase HPLC column were collected and samples equivalent to exudate from about two seedlings were assayed for activity as described in Materials and Methods. Luminescence was measured with the charged couple device camera. Fractions that induced Serratia liquefaciens PL10 luminescence are indicated by light green bars. These same fractions induced swarming of MG44 (not shown). Fractions that induced luminescence in the LuxRI' reporter (pSB401) are indicated in black, in the AhyRI' reporter (pSB536) in red, and in the LasRI' reporter (pSB1075) in dark green. Relative inhibition of $\mathrm{C}_{4}$-HSL-induced violacein synthesis in Chromobacterium violaceum CV026 is shown in purple, and was equal to $100 \%$ in fractions 8 and 9 . Thick gray line indicates gradient of increasing acetonitrile concentration (0-100\%) used for elution; thin black line indicates $A_{254}(0-2)$. Similar results were obtained in repeated fractionations. 
As shown in Figure 6, some important separation of different substances with AHL mimic activity was obtained by chromatographic fractionation of pea exudate extract on a $\mathrm{C}_{18}$ reverse phase column. The absorbance of fractions at $254 \mathrm{~nm}$ is shown as an (arbitrary) indication of where the bulk of the material in the exudate extract eluted. None of the fractions from the $\mathrm{C}_{18}$ column contained substances that appreciably stimulated violacein synthesis in CV026 (data not shown). This is consistent with the failure of live pea seedlings to induce detectable violacein synthesis (Fig. 1A). When samples of each fraction equivalent to exudate from approximately two seedlings were assayed with CV026 and the luminescence reporters, all of the activity detectable by the CV026 indirect assay and some of the activity detected with the PL10, LasRI', and AhyRI' reporters and the S. liquefaciens MG44 reporter eluted in or near the void volume (fractions 8 to 15), suggesting that the compounds responsible for these activities could not bind to the $\mathrm{C}_{18}$ column because they are dominantly hydrophilic or ionic. Several activities detectable with the PL10, MG44, LasRI', AhyRI', and LuxRI' reporters eluted in fractions near the middle of the acetonitrile gradient (fractions 22 to 45). In addition, activities detectable with the AhyRI' and LasRI' reporters appeared in fractions near the end of the gradient (fractions 50 to 57).

When larger samples of the HPLC fractions were assayed (equivalent to exudate from six seedlings), one major new peak of PL10 activity was detectable in fractions 50 to 53 (data not shown). On a per seedling basis, the relative luminescence induced by material in this peak was about $70 \%$ of the +AHL control, likely accounting for most of the PL10 luminescence seen with inoculated seedlings (Fig. 5). It will be of interest to determine whether fractions that stimulated responses in two or three different reporter strains contain one compound acting on two or three reporters or several different compounds, each acting on a separate reporter. Further purification and analysis to identify the active substances are in progress.

\section{DISCUSSION}

The halogenated furanones from $D$. pulchra provided the first clear example of AHL mimic compounds produced by a eukaryote (Givskov et al. 1996; Kjelleberg et al. 1997; Manefield et al. 1999). While quite limited, our initial examination of other plant species indicates that the synthesis of AHL signal-mimic substances may prove to be fairly general among higher plants. The apparent synthesis and secretion of AHL mimic compounds by diverse plant species substantially broadens the range of plant-microbe interactions where signalmimic compounds might play important roles. Future investigations to detect AHL mimic compounds in additional plants could be valuable in exploring this possibility and in the search for new compounds to protect plants as well as humans and other animals from pathogenic bacteria.

The AHL signal-mimic activities detected in pea exudate and with live seedlings do not appear to be artifactual responses of the bacterial reporter strains. Pea seedlings and exudates inhibited three different behaviors under AHL control in $C$. violaceum. In $S$. liquefaciens MG44, the initiation of swarming depends on surface-stimulated induction of the $f l h D C$ operon, leading to formation of hyperflagellated cells, as well as on AHL-regulated serrawettin synthesis. Thus, swarming is not as specifically dependent on AHL binding as PL10 bioluminescence (Givskov et al. 1997; Lindum et al. 1998). In control experiments, the addition of live pea seedlings or exudate extract preparations did not appear to stimulate the $f l h D C$ operon, as measured by phospholipase assays (data not shown). Phospholipase is under control of the flhDC operon (Eberl et al. 1996). A further indication that swarming of $S$. liquefaciens MG44 was specifically induced by plant compounds acting as AHL mimics is the tightly parallel induction of MG44 swarming and PL10 bioluminescence by live seedlings of pea (Fig. 2), by other plants tested in Table 1, and by at least three separate fractions of pea exudate (Fig. 6). Based on such parallel induction of both swarming and swrA gene expression, and on evidence for the absence of serrawettin-like surfactants in the exudate, or compounds that activated the $f l h D C$ operon, or compounds that affected growth of the reporter strains, it seems likely that pea seedlings secrete compounds that specifically activate the SwrR receptor governing swrA expression and serrawettin synthesis.

Similarly, the activation of the LuxRI', AhyRI', and LasRI' plasmid reporters by seedlings of various plant species and by methanol extracts of pea seedling exudate suggests that these plants secrete compounds that specifically activate the AHL receptors, most likely by binding directly to the receptor protein. Our results with the PL10 and E. coli plasmid reporters appear to provide the first example of positively acting AHL signal-mimic compounds produced by eukaryotic organisms. It is worth noting, however, that others have shown that compounds that inhibit AHL-stimulated gene expression in cells with single copies of a LuxR-like receptor can show stimulatory activity when the receptor is present in multiple copies (Zhu et. al. 1998). Thus, plant mimic compounds that stimulate the multicopy plasmid AHL reporters may act as competitive inhibitors of AHL-induced behaviors in wild-type bacteria.

Substances that can block quorum sensing in bacteria have been recently discussed as potentially valuable anti-infective agents for medicine (Finch et al. 1998). The substantial inhibition of three distinct AHL-inducible, CviR-regulated behaviors in CV026, and the partial reversal of such inhibition by addition of more $\mathrm{C}_{4}$-HSL, makes it reasonable to suggest that pea plants secrete one or more compounds that specifically interfere with perception of AHL signals by the CviR receptor in the CV026 reporter strain. It will be of interest to learn whether exudates from higher plants contain substances that specifically inhibit other AHL-induced activities.

Further studies, preferably with pure mimic compounds, will be needed to rigorously establish the molecular mechanism(s) by which the AHL mimic compounds act. For example, plants might secrete "pseudo" mimic compounds that interfere with AHL synthesis or with AHL transport as well as "real" mimic compounds, like the halogenated furanones, that interact directly with the AHL receptor protein. It is of interest that Pseudomonas aeruginosa secretes cyclic dipeptides that act as AHL mimic compounds (Holden et al. 1999). The bacterial dipeptides appear to interact directly with AHL receptors and can either activate or inhibit receptor-mediated transcription, depending on the receptor.

Our initial attempts to purify the AHL mimic activity in pea exudates indicate that pea secretes at least one substance with 
inhibitory activity in the CV026 reporter and perhaps half a dozen or more different substances that stimulate one or more of the other AHL reporter strains. Further fractionation may reveal additional activities. The sum of the relative activities observed in the HPLC fractions for each reporter agrees reasonably well on a per seedling basis with the total relative activity seen in Figure 5 with live pea seedlings, indicating that most of the activities present on the seedling surfaces were probably recovered and detected after fractionation. However, given the limited range of concentrations tested and the unknown sensitivity of the reporters toward particular mimic compounds, we suspect that the relative luminescence elicited by substances in these HPLC fractions may not be a very reliable indicator of either the amount or potency of the AHL mimic substances present. We also note that the mimic activities detected in fractions from the $\mathrm{C}_{18}$ column probably represent just those compounds that can interact with the CviR, LuxR, AhyR, LasR, and SwrR receptor proteins. The use of additional reporter strains that have AHL receptors with different binding specificities or affinities might well reveal additional AHL mimic activities. The synthesis and secretion of a diversity of AHL mimic substances, some acting positively in certain bacterial species, some acting negatively in other bacterial species, could be important to the coevolved biology of interaction between plants and their associated bacteria.

\section{MATERIALS AND METHODS}

\section{Bacterial strains and growth conditions.}

Stock cultures of S. liquefaciens MG1 wild-type and the reporter strains MG44 (swrI mutant $\mathrm{km}^{\mathrm{r}}$ ) and PL10 (swrI mutant, swrA::Tn5luxAB $\mathrm{km}^{\mathrm{r}} \mathrm{tc}^{\mathrm{r}}$ ), generously provided by $\mathrm{M}$. Givskov and S. Kjelleberg, were cultured on AB medium with glucose and Casamino Acids as described by Givskov et al. (1997) with km50 or tc10, respectively. Cultures of $C$. violaceum wild-type ATCC 31532 and the reporter strain CV026 $\left(\mathrm{sm}^{\mathrm{r}}\right.$ miniTn5 $\mathrm{Hg}^{\mathrm{r}}$ cviI::Tn5xylE $\left.\mathrm{km}^{\mathrm{r}}\right)$ were generously provided by $\mathrm{P}$. Williams, and cultured in LB (Luria-Bertani) broth. Lux plasmid AHL reporters E. coli JM109 pSB401 (luxRI':luxCDABE $\mathrm{tc}^{\mathrm{r}}$ ), E. coli JM109 pSB536 (ahyRI'::luxCDABE ap ${ }^{\mathrm{r}}$ ), and E. coli JM109 pSB1075 (lasRI'::luxCDABE ap ${ }^{\mathrm{r}}$ ), a generous gift from S. Swift, were grown in LB broth with appropriate antibiotics as described by Winson et al. (1998). Pseudomonas aureofaciens 30-84 and its phzI mutant, P. aureofaciens 30-84I (Wood et al.1997), a gift of F. Gong, were cultured on LB. All strains were maintained as glycerol stocks at $-80^{\circ} \mathrm{C}$ and small samples were subcultured into fresh medium with antibiotics (when necessary) for the assays.

\section{Plant material.}

Pea (Pisum sativum) cv. Extra Early Alaska (Livingston Seed, Columbus, $\mathrm{OH}$ ) was surface sterilized for $90 \mathrm{~min}$ in $95 \%$ ethanol, followed by $60 \mathrm{~min}$ in $70 \%$ commercial Chlorox bleach. Crown vetch (Coronilla varia) cv. Penngift seeds (Livingston Seed) were scarified for $10 \mathrm{~min}$ in concentrated sulfuric acid, then surface sterilized in $95 \%$ ethanol for $30 \mathrm{~min}$ and in 50\% Chlorox for $30 \mathrm{~min}$. Seeds of Medicago truncatula genotype A17 (a gift from D. Cook) were surface sterilized for $60 \mathrm{~min}$ in $95 \%$ ethanol, followed by a $10 \mathrm{~min}$ treatment with full-strength commercial Chlorox bleach. Soybean
(Glycine max) cv. Flint (from S. St. Martin), Arabidopsis thaliana ColO (from J.C. Jang), tomato (Lycopersicon esculentum) cv. Rutgers Select VFA (Geo. W. Park Seed, Greenwood SC), rice (Oryza sativa) cv. Nipponbare (from G. L. Wang), and romaine lettuce (Lactuca sativa) cv. Paris Island (Livingston Seed) were surface sterilized for $30 \mathrm{~s}$ in $95 \%$ ethanol and $15 \mathrm{~min}$ in 50\% commercial Chlorox bleach.

The surface-sterilized seeds were extensively rinsed with sterile tap water, imbibed for 4 to $6 \mathrm{~h}$ in sterile water, and germinated in the dark on moist Whatman \#1 paper. After the seedlings were harvested, the germination paper was touched to the surface of an LB agar plate to check for microbial contamination. Only uncontaminated seedlings were used for the bioassays.

\section{Preparation of pea exudates and extracts.}

Batches of approximately 100 aseptically grown, 7-day-old pea seedlings (and the washed, autoclaved Whatman filter paper used to maintain moisture for the seedlings) were flooded with $100 \mathrm{ml}$ of sterile water and gently swirled for several minutes to collect the crude seedling rinsate. One-hundredmicroliter samples of the rinsates were plated on LB agar to check for microbial contamination, and contaminated batches were discarded.

Contaminant-free rinsates were spun down, filtered, frozen, and lyophilized. On average, 5 to $10 \mathrm{mg}$ of dry crude exudate was collected per 100 seedlings. Lyophilized exudate preparations were mixed with $50 \%$ methanol:water $(1 \mathrm{ml}$ per $10 \mathrm{mg}$ of lyophilized material) and centrifuged after $15 \mathrm{~min}$ to remove insoluble materials. The $50 \%$ methanol extract was used for routine assays of violacein, swarming, and exoenzyme activity, as shown in Figures 2 and 3. For further purification of activities, an additional volume of $100 \%$ methanol was added to the $50 \%$ methanol extract to bring the extracts to $95 \%$ methanol. Isopropanol (1 volume of isopropanol to 4 volumes of $95 \%$ methanol:water) was then added to precipitate inactive contaminating materials. After $15 \mathrm{~min}$ of incubation, the insoluble material (approximately $25 \%$ by mass) was removed by centrifugation. All extraction steps were carried out at room temperature. The organic solvents were removed by rotary evaporation under vacuum at $30^{\circ} \mathrm{C}$. The resulting yellow viscous exudate extract was dissolved in $1.0 \mathrm{ml}$ of water per $10 \mathrm{mg}$ of dried residue for the assays in Figures 3 and 4.

\section{HPLC of pea extract.}

For reverse phase HPLC, $1 \mathrm{ml}$ of a $30 \%$ methanol:water solution of the isopropanol-precipitated extract, prepared as described above, containing exudate from about 650 seedlings, was injected onto a water-equilibrated, semi-preparative $\mathrm{C}_{18}$ column (Whatman Partisil 10 ODS-3). The column was eluted for $15 \mathrm{~min}$ in water, followed for $45 \mathrm{~min}$ with a linear water: acetonitrile gradient at a flow rate of $3 \mathrm{ml} / \mathrm{min}$. Absorbance was monitored at $254 \mathrm{~nm}$. Fractions were collected every minute and bioassayed with the reporters as described below.

\section{Bioassays for AHL mimic compounds from plants: Violacein and phenazine production.}

C. violaceum $\mathrm{CV026,}$. aureofaciens $30-84$, and a $\mathrm{C}_{6}-\mathrm{HSL}$ negative mutant, 30-84I, were grown in LB broth overnight on a shaker at $27^{\circ} \mathrm{C}$. Five hundred microliters of the cultures, 
containing approximately $2-3 \times 10^{9}$ bacteria, was spun down and resuspended in $5 \mathrm{ml}$ of warm LB containing $0.5 \%$ agar. For indirect CV026 bioassays to measure inhibition of violacein synthesis by seedlings or exudate, $3.5 \mu \mathrm{g}$ of $\mathrm{C}_{4}$-HSL dissolved in $7 \mu \mathrm{l}$ of ethyl acetate was added to the soft agar suspension of bacteria. For assays with live seedlings (Fig. 1, Table 1), the bioassay agar suspensions were poured on a surface of regular LB agar, and aseptically grown seedlings were placed on the thin layer of soft agar containing the bacteria. As controls, glass fiber disks containing appropriate AHLs were placed on the surface of the bioassay agar. To semiquantitatively estimate the ability of seedling exudates or exudate extract preparations to inhibit AHL-induced pigment synthesis, 20- to 30- $\mu$ l samples from a two- or threefold serial dilution of the exudate or extract (with organic solvents removed by evaporation) were added to the wells of a 96-well Falcon microtiter plate and mixed with $50 \mu$ of the warm bioassay agar containing $\mathrm{CV} 026$ and $\mathrm{C}_{4}$-HSL (or P. aureofaciens 30-84 with no AHL) as described above. The plates were incubated for 15 to $25 \mathrm{~h}$ at $27^{\circ} \mathrm{C}$. Violacein was extracted from the wells with $700 \mu \mathrm{l}$ of $95 \%$ ethanol, and absorbance measured at $575 \mathrm{~nm}$. The reversibility of pea exudate-induced inhibition of violacein synthesis was tested by adding an additional $0.5 \mu \mathrm{g}$ of $\mathrm{C}_{4}$-HSL per ml either 0 or $4 \mathrm{~h}$ after mixing of the CV026 bioassay agar with one seedling equivalent of the pea exudate extract and incubation for $20 \mathrm{~h}$.

To test whether compounds in pea root exudates can degrade or immobilize $\mathrm{C}_{4}$-HSL, HPLC fractions containing violacein synthesis inhibiting activity from 25 pea seedlings were re-dissolved in $250 \mu \mathrm{l}$ of sterile, distilled water and mixed with a $50-\mu$ l solution containing $25 \mu \mathrm{g}$ of $\mathrm{C}_{4}$-HSL in water and incubated overnight. As a control, $300 \mu \mathrm{l}$ of sterile, distilled water containing $25 \mu \mathrm{g}$ of $\mathrm{C}_{4}$-HSL was incubated similarly. $\mathrm{C}_{4}$-HSL was extracted with ethyl acetate $(2 \times 2 \mathrm{ml})$ and the solvent removed by rotary evaporation. The $\mathrm{C}_{4}$-HSL residue was re-dissolved in sterile, distilled water and samples from a twofold dilution series assayed by the semiquantitative microtiter plate method described above.

\section{Luminescence bioassays with the CCD camera.}

S. liquefaciens PL10 was grown overnight at $27^{\circ} \mathrm{C}$ in $\mathrm{AB}$ with glucose and Casamino Acids (Eberl et al. 1996) with tc10. E. coli JM109 pSB401 (LuxRI'), E. coli JM109 pSB536 (AhyRI'), and E. coli JM109 pSB1075 (LasRI') were grown at $37^{\circ} \mathrm{C}$ in LB with tc10 or amp 100 . The bacterial suspensions were then centrifuged, and the pellets resuspended in 10 volumes of sterile water to an $A_{600}$ of approximately 0.10. Aseptically grown, etiolated seedlings were completely submerged in the suspension of bacteria, then gently blotted on a piece of sterile, absorbent tissue and incubated on the surface of $A B$ agar at $27^{\circ} \mathrm{C}$ (for PL10) or LB agar at $37^{\circ} \mathrm{C}$ (for the plasmid reporters) for 5 to $9 \mathrm{~h}$. As controls, suspensions of the reporter strains were inoculated onto small slabs $(3 \times 20 \times 70 \mathrm{~mm})$ of nutrient agar, incubated, and then observed at the same time as the seedlings. For the positive controls, the agar slabs contained a high, maximally activating concentration of $\mathrm{C}_{4}$-HSL for the LuxRI' and AhyRI' $(2 \mu \mathrm{M})$ and PL10 $(6 \mu \mathrm{M})$ reporters or 3-oxo- $\mathrm{C}_{12}$-HSL $(5 \mu \mathrm{M})$ for the LasRI' reporter. No AHL was added to the agar slabs of the negative controls. Images of the seedlings and luminescing bacteria were taken with a Hamamatsu C2400 intensified CCD camera and analyzed with an Argus-20 image processor. The false color images were superimposed on the digital images of the seedlings in Adobe Photoshop version 4.0.1. The total number of photons emitted and counted per second from the entire surface area of the seedling (or corresponding streak colonies for the controls) was determined. The relative luminescence of the reporter strain growing on an inoculated seedling was then calculated by subtracting the background luminescence of the uninduced reporter strain (growing on agar containing no AHL), and then expressing this net luminescence as a percentage of the luminescence of the positive controls. Relative luminescence values were normalized to equal numbers of reporter bacteria based on recovery of the reporter bacteria from seedling and agar surfaces and plating on agar to determine the number of CFU.

For quantitative bioluminescence bioassays, 20 to $30 \mu \mathrm{l}$ of seedling exudate extract or HPLC fractions was placed onto 11-mm-diameter Whatman GFC glass fiber disks. After evaporation of the samples to dryness in a laminar flow hood, the disks were inoculated with $10 \mu \mathrm{l}$ of 10 -fold-diluted cultures of the luminescence reporters and then incubated for 5 to $6 \mathrm{~h}$ in the shallow wells of a 96-well microtiter plate lid with $25 \mu \mathrm{l}$ of $\mathrm{AB}$ glucose/Casamino Acids medium (PL10) or LB (plasmid reporters) prior to $\mathrm{CCD}$ camera measurement of luminescence. Luminescence bioassays with PL10 required exposure to n-decanal vapor $(30 \mu \mathrm{l}$ in a large lidded box for 8 to $20 \mathrm{~min}$ ) prior to luminescence measurements.

\section{Luminescence assays with X-ray film.}

For routine, semiquantitative detection of lux-inducing activity induced by pea exudates, extracts, or HPLC fractions, samples (or samples from a twofold dilution series) were incubated on filter disks in the presence of the lux reporter strains as described above. Luminescence was then detected by placing the microtiter plate lid on a piece of Kodak BioMax Light-1 X-ray film for 4 to $8 \mathrm{~min}$. The incubation times required to induce maximal luminescence and maximal net luminescence above background varied for each of the lux reporters, requiring about 4 to $6 \mathrm{~h}$ for the LuxRI', AhyRI', and LasRI' reporters and about 9 to $11 \mathrm{~h}$ for the PL10 reporter. The luminescence of reporter strains inoculated onto seedlings could be readily detected in the same manner.

\section{Swarming assays.}

S. liquefaciens MG44 and PL10 were grown overnight in $\mathrm{AB}$ with Casamino Acids and glucose with amp50 or tc10 at $27^{\circ} \mathrm{C}$ to a late log phase. The cells were then pelleted, and resuspended in 10 volumes of sterile water. Aseptically grown seedlings or sterile toothpicks were dipped in the reporter suspensions, rinsed in sterile water, blotted on a sterile, absorbent tissue, and incubated for 10 to $15 \mathrm{~h}$ on a surface of $\mathrm{AB}$ agar with glucose and Casamino Acids as in Givskov et al. 1997. Swarm colonies were photographed with a Polaroid camera. Swarm assays were also conducted in 24-well microtiter plates by inoculating the surface of agar containing seedling exudate or extract with the MG44 reporter strain followed by overnight incubation.

\section{Protease assays.}

Late $\log$ phase suspensions of $C$. violaceum CV026 (10 $\mu \mathrm{l})$ were added to $1 \mathrm{ml}$ of fresh $1 / 10$ strength LB medium con- 
taining $0.5 \mu \mathrm{g}$ of $\mathrm{C}_{4}$-HSL per $\mathrm{ml}$ and $0,1,5$, or 15 seedling equivalents of pea exudate extract, with the organic solvents previously removed by evaporation. After $20 \mathrm{~h}$ of shake culture growth at $27^{\circ} \mathrm{C}$, the bacteria were removed by centrifugation and the culture supernatants assayed for protease activity with azocasein (Sigma Chemical, St. Louis, MO) as described (Gerhardt et al. 1994). Similarly, C. violaceum wild type was inoculated into $1 / 10 \mathrm{LB}$ medium with or without pea exudate extract and with or without 3-oxo- $\mathrm{C}_{12}$-HSL (2.3 $\mu \mathrm{g} / \mathrm{ml}$ ) and assayed after $20 \mathrm{~h}$ incubation for protease activity on azocasein.

\section{Chitinase assays.}

For exochitinase (p-nitrophenyl- $\beta$-D- $N$-acetylglucosaminidase) activity, $10 \mu \mathrm{l}$ of CV026 overnight LB shake culture was inoculated into $1 / 10$ strength LB-based synthetic medium (SM) with colloidal chitin prepared as described by Chernin et al. (1998) containing $0.5 \mu \mathrm{g}$ of $\mathrm{C}_{4}$-HSL per $\mathrm{ml}$ and $0,1,5$, or 15 seedling equivalents of a pea exudate extract. After $20 \mathrm{~h}$ of incubation on a shaker at $27^{\circ} \mathrm{C}$, exochitinase activity in culture supernatants was measured with p-nitrophenyl- $\beta$-D- $N$ acetylglucosaminide (Sigma) as described in Chernin et al. (1998). Endochitinase activity was assayed in 1/10 LB-based SM agar with colloidal chitin (as in Chernin et al. 1998) containing $0.5 \mu \mathrm{g}$ of $\mathrm{C}_{4}$-HSL per $\mathrm{ml}$ and $0,1,5$, or 15 seedling equivalents of a pea exudate extract per $1 \mathrm{ml}$ of the medium. The plates were stab inoculated with CV026 and chitin degradation estimated by clearing of the medium surrounding the bacterial colonies after 3 to 4 days of incubation.

\section{Phospholipase assay.}

For S. liquefaciens cultures (MG44 and PL10) incubated with pea seedling extracts, phospholipase activity was measured in egg yolk agarose as described by Givskov and Molin 1993.

In general, growth of bacteria was monitored in shake cultures by both turbidimetric measurements at $A_{600}$ and by dilution platings of gently sonicated cultures on LB agar. All assays were done in duplicate and all experiments were conducted at least twice with essentially the same results. The $\mathrm{C}_{4}$-HSL used in this study was synthesized as previously described (Chhabra et al. 1993) and verified by HPLC fractionation and MS analysis, while the 3 -oxo- $\mathrm{C}_{12}$-HSL was provided by B. Iglewski.

\section{ACKNOWLEDGMENTS}

We thank John Streeter, David Coplin, Paul Williams, and the editorial reviewers for critical reading of the manuscript and helpful comments, Barbara Iglewski for supplying us with 3-oxo- $\mathrm{C}_{12}-\mathrm{HSL}$, and Michael Givskov, Staffan Kjelleberg, Simon Swift, Paul Williams, and Fang-Chen Gong for providing the reporter strains used in these studies. Jim Metzger provided invaluable help and advice with HPLC fractionation of samples. We are much indebted to Brian Ahmer for generously making his Hamamatsu CCD camera and image analysis system available to us and guiding us in its use. Partial support for salaries, supplies, and publication costs was provided by state and federal funds appropriated to the Ohio Agricultural Research and Development Center, Ohio State University. OARDC manuscript no. 99-18.

\section{LITERATURE CITED}

Cha, C., Gao, P., Chen, Y.-C., Shaw, P. D., and Farrand, S. K. 1998. Production of acyl-homoserine lactone quorum-sensing signals by gramnegative plant-associated bacteria. Mol. Plant-Microbe Interact. 11:
1119-1129.

Chernin, L. S., Winson, M., Thompson, J. M., Haran, S., Bycroft, B. W., Chet, I., Williams, P., and Stewart, G. S. A. B. 1998. Chitinolytic activity in Chromobacterium violaceum: Substrate analysis and regulation by quorum sensing. J. Bacteriol. 180:4435-4441.

Chhabra, S. R., Stead, P., Bainton, N. J., Salmond, G. P. C., Stewart, G. S. A. B., Williams, P., and Bycroft, B. W. 1993. Autoregulation of carbanem biosynthesis in Erwinia carotovora by analogues of $\mathrm{N}$-(3oxohexanoyl)-L-homoserine lactone. J. Antibiot. 46:441-454.

Choi, S. H., and Greenberg, E. P. 1992. Genetic dissection of DNA binding and luminescence gene activation by the Vibrio fischeri LuxR protein. J. Bacteriol. 174:4064-4069.

Dunny, G. M., and Leonard, B. A. B. 1997. Cell-cell communication in gram-positive bacteria. Annu. Rev. Microbiol. 51:527-564.

Eberl, L., Molin, S., and Givskov, M. 1999. Surface motility of Serratia liquefaciens MG1. J. Bacteriol. 181:1703-1712.

Eberl, L., Winson, M. K., Sternberg, C., Stewart, G. S. A. B., Christiansen, G., Chhabra, S. R., Bycroft, B., Williams, P., Molin, S., and Givskov, M. 1996. Involvement of $N$-acyl-L-homoserine lactone autoinducers in controlling the multicellular behavior of Serratia liquefaciens. Mol. Microbiol. 20:127-136.

Finch, R. G., Pritchard, D. I., Bycroft, B. W., Williams, P., and Stewart, G. S. A. B. 1998. Quorum sensing: A novel target for anti-infective therapy. J. Antimicrob. Chemother. 42:569-571.

Flavier, A. B., Clough, S. J., Schell, M. A., and Denny, T. P. 1997. Identification of 3-hydroxypalmitic acid methyl ester as a novel autoregulator controlling virulence in Ralstonia solanacearum. Mol. Microbiol. 26:251-259.

Fuqua, C., Winans, S., and Greenberg, E. P. 1996. Census and consensus in bacterial ecosystems: The LuxR-LuxI family of quorum-sensing transcriptional regulators. Annu. Rev. Microbiol. 50:727-751.

Gerhardt, P., Murray, R. G. E., Wood, W. A., and Krieg, N. R. 1994. Methods for General and Molecular Bacteriology. Am. Soc. Microbiol., Washington, DC.

Givskov, M., de Nys, R., Manefield, M., Gram, L., Maximilllen, R., Eberl, L., Molin, S., Steinberg, P. D., and Kjelleberg, S. 1996. Eukaryotic interference with homoserine lactone-mediated prokaryotic signaling. J. Bacteriol. 178:6618-6622.

Givskov, M., Eberl, L., and Molin, S. 1997. Control of exoenzyme production, motility and cell differentiation in Serratia liquefaciens. FEMS Microbiol. Lett. 148:115-122.

Givskov, M., and Molin, S. 1993. Secretion of Serratia liquefaciens phospholipase from Escherichia coli. Mol. Microbiol. 8:229-242.

Glessner, A., Smith R. S., Iglewski, B. H., and Robinson, J. B. 1999. Roles of Pseudomonas aeruginosa las and rhl quorum-sensing systems in control of twitching motility. J. Bacteriol. 81:1623-1629.

Grimont, P. A. D., and Grimont, F. 1978. The genus Serratia. Annu. Rev. Microbiol. 32:221-248.

Gupta, C. P., Sharma, A., Dubey, R. C., and Maheshwari, D. K. 1999. Pseudomonas aeruginosa (GRC1) as a strong antagonist of Macrophomina phaseolina and Fusarium oxysporum. Cytobios 99:183-189.

Holden, M. T. G., Chhabra, S. R., de Nys, R., Stead, P., Bainton, N. J., Hill, P. J., Manefield, M., Kumar, N., Labatte, M., England, D., Rice, S., Givskov, M., Salmond, G. P. C., Stewart, G. S. A. B., Bycroft, B. W., Kjelleberg, S., and Williams, P. 1999. Quorum-sensing cross talk: Isolation and chemical characterization of cyclic dipeptides from Pseudomonas aeruginosa and other Gram-negative bacteria. Mol. Microbiol. 33:1254-1266.

Horinouchi, S. 1999. $\gamma$-Butyrolactones that control secondary metabolism and cell differentiation in Streptomyces. Pages 193-209 in CellCell Signalling in Bacteria. G. M. Dunny and S. Winans, eds. Am. Soc. Microbiol., Washington, DC.

Hussain, A., and Vancura, V. 1970. Formation of biologically active substances by rhizosphere bacteria and their effect on plant growth. Folia Microbiol. 15:468-478.

Kjelleberg, S., Steinberg, P., Givskov, M., Gram, L., Manefield, M., and de Nys, R. 1997. Do marine natural products interfere with prokaryotic AHL regulatory systems? Aquat. Microb. Ecol. 13:85-93.

Lazazzera, B. A., Palmer, T., Quisel, J., and Grossman, A. D. 1999. Celldensity control of gene expression and development in Bacillus subtilis. Pages 27-46 in: Cell-Cell Signalling in Bacteria. G. M. Dunny and S. Winans, eds. Am. Soc. Microbiol., Washington, DC.

Lindum, P. W., Anthoni, U., Chrirstophersen, C.,. Eberl, L., Molin, S., and Givskov, M. 1998. N-acyl-L-homoserine lactone autoinducers 
control production of an extracellular lipopeptide biosurfactant required for swarming motility of Serratia liquefaciens MG1. J. Bacteriol. 180:6384-6388

Manefield, M., de Nys, R., Kumar, N., Read, R., Givskov, M., Steinberg, P., and Kjelleberg, S. 1999. Evidence that halogenated furanones from Delisea pulchra inhibit acylated homoserine lactone (AHL)-mediated gene expression by displacing the AHL signal from its receptor protein. Microbiology 145:283-291.

McClean, K. H., Winson, M. K., Fish, L., Taylor, A., Chhabra, S. R., Camara, M., Daykin, M., Lamb, J. H., Swift, S., Bycroft, B., Stewart, G. S A. B., and Williams, P. 1997. Quorum sensing and Chromobacterium violaceum: Exploitation of violacein production and inhibition of the detection of $N$-acylhomoserine lactones. Microbiology 143: 3703-3711.

Miller, D. P., Blevins, W. T., Steele, D. B., and Stowers, M. D. 1988. A comparative study of virulent and avirulent strains of Chromobacterium violaceum. Can. J. Microbiol. 34:249-255.

Pesci, E. C., and Iglewski, B. H. 1999. Quorum sensing in Pseudomonas aeruginosa. Pages 147-157 in: Cell-Cell Signalling in Bacteria. G. M. Dunny and S. Winans, eds. Am. Soc. Microbiol., Washington, DC.

Pesci, E. C., Milbank, J. B. J., Pearson, J. P., McKnight, S., Kende, A. S., Greenberg, E. P., and Iglewski, B. H. 1999. Quinolone signaling in the cell-to-cell communication system of Pseudomonas aeruginosa. Proc. Natl. Acad. Sci. USA 96:11229-11234.

Pierson, L. S., III, and Thomashow, L. S. 1992. Cloning and heterologous expression of the phenazine biosynthetic locus of Pseudomonas aureofaciens 30-84. Mol. Plant-Microbe Interact. 5:330-339.

Pierson, L. S., III, Wood, D. W., and Beck von Bodman, S. 1999. Quorum sensing in plant-associated bacteria. Pages 101-115 in: Cell-Cell Signaling in Bacteria. G. M. Dunny and S. Winans, eds. Am. Soc. Microbiol., Washington, DC.

Pierson, E. A., Wood, D. W., Cannon, J. A., Blachere, F. M., and Pierson, L. S., III. 1998. Interpopulation signaling via $N$-acyl-homoserine lactones among bacteria in the wheat rhizosphere. Mol. Plant Microbe Interact. 11:1078-1084.

Poplawsky, A. R., Chun, W., Slater, H., Daniels, M. J., and Dow, M. 1998. Synthesis of extracellular polysaccharide, extracellular enzymes and xanthomonadin in Xanthomonas campestris: Evidence for the involvement of two intercellular regulatory signals. Mol. Plant Microbe
Interact. 11:68-70.

Rodelas, B., Lithgow, J. K., Wisniewski-Dye, F., Hardman, A., Wilkinson, A., Economou, A., Williams, P., and Downie, J. A. 1999. Analysis of quorum-sensing-dependent control of rhizosphere-expressed (rhi) genes in Rhizobium leguminosarum bv. viciae. J. Bacteriol. 181: 3816-3823.

Stevens, A. M., and Greenberg, E. P. 1999. Transcriptional activation by LuxR. Pages 231-242 in: Cell-Cell Signalling in Bacteria. G. M. Dunny and S. Winans, eds. Am. Soc. Microbiol., Washington, DC.

Swift, S., Karlyshev, A. V., Fish, L., Durant, E. L., Winson, M. K., Chhabra, S. R., Williams, P., MacIntyre, S., and Stewart, G. S. A. B. 1997. Quorum sensing in Aeromonas hydrophila and Aeromonas salmonicida: Identification of the LuxRI homologs AhyRI and AsaRI and their cognate $\mathrm{N}$-acylhomoserine lactone signal molecules. J. Bacteriol. 179:5271-5281.

Swift, S., Williams, P., and Stewart, G. S. A. B. 1999. $N$-acylhomoserine lactones and quorum sensing in proteobacteria. Pages 291-313 in: Cell-Cell Signalling in Bacteria. G. M. Dunny and S. Winans, eds. Am. Soc. Microbiol., Washington, DC.

van Egeraat, A. W. S. M. 1975. Changes in free ninhydrin-positive compounds of young pea plants as affected by different nutritional and environmental conditions. Plant Soil 42:15-36.

Whiteley, M., Lee, K. M., and Greenberg, E. P. 1999. Identification of genes controlled by quorum sensing in Pseudomonas aeruginosa. Proc. Natl. Acad. Sci. USA 96:13904-13909.

Winson, M. K, Swift, S., Fish, L., Throup, J. P., Jorgensen, F., Chhabra, S. R., Bycroft, B. W., Williams, P., and Stewart, G. S. A. B. 1998 Construction and analysis of luxCDABE-based plasmid sensors for investigating $N$-acyl homoserine lactone-mediated quorum sensing. FEMS Microbiol. Lett. 163:185-192.

Wood, D. W., Gong, F., Daykin, M. M., Williams, P., and Pierson, L. S. III. 1997. $N$-acyl-homoserine-lactone mediated regulation of phenazine gene expression by Pseudomonas aureofaciens 30-84 in wheat rhizosphere. J. Bacteriol. 179:7663-7670.

Zhu, J., Beaber, J. W., Moré, M. I., Fuqua, C., Eberhard, A., and Winans, S. C. 1998. Analogs of the autoinducer 3-oxooctanoyl-homoserine lactone strongly inhibit activity of the TraR protein of Agrobacterium tumefaciens. J. Bacteriol. 180:5398-5405. 